\title{
Malgorzata Marks-Krzyszkowska*
}

(iD) https://orcid.org/0000-0001-9430-8476

\section{Jarosław Linka**}

(iD) https://orcid.org/0000-0002-5951-1716

\section{IDEA WSPÓLZARZĄDZANIA - SZANSA \\ CZY OGRANICZENIE UCZESTNICTWA PUBLICZNEGO KOBIET NA WSI}

\begin{abstract}
Abstrakt. Celem artykułu jest znalezienie odpowiedzi na pytanie o to, czy realizowana na obszarach wiejskich koncepcja współzarządzania (tzw. new rural governance) umożliwia, tradycyjnie marginalizowanym w sferze publicznej, kobietom udział we współzarządzaniu gminą. Rozważania opierają się na przeglądzie międzynarodowej literatury przedmiotu i koncentrują się na określeniu zakresu uczestnictwa w szeroko rozumianym współzarządzaniu gminą i ewentualnych przyczyn jego ograniczeń. Jak wynika $\mathrm{z}$ analiz, mimo że zakres partycypacji kobiet we współzarządzaniu gminą nominalnie zwiększa się, to realnie często jest ograniczony do uczestnictwa bez możliwości wpływu na decyzje i nierzadko ma fasadowy charakter.
\end{abstract}

Słowa kluczowe: kobiety na wsi, uczestnictwo publiczne, współzarządzanie.

\section{Wstęp}

Na przestrzeni ostatnich dziesięcioleci cele i wzory zarządzania (także obszarami wiejskimi) uległy istotnym i wielowymiarowym przeobrażeniom. Przede wszystkim współcześnie zarządzanie przyjmuje bardziej demokratyczne formy, poprzez zwiększanie możliwości uczestniczenia obywateli w procesach decyzyjnych (Dryzek 2002). Procesy współzarządzania (new governance ${ }^{1}$ ), w założeniach koncepcyjnych, umożliwiają cieszącym się wzajemnym zaufaniem interesariuszom szeroki udział społeczny i dzielenie się informacjami (Eversole,

* Dr, Katedra Gospodarki Samorządu Terytorialnego, Wydział Ekonomiczno-Socjologiczny, Uniwersytet Łódzki, ul. Rewolucji 1905 r.nr 37, 90-214 Łódź, e-mail: malgorzata.marks@uni.lodz.pl

** Mgr, Instytut Organizacji i Zarządzania w Przemyśle - Orgmasz, ul. Żelazna 87, 00-879 Warszawa, e-mail: jarek.linka@gmail.com

${ }^{1}$ Termin new governance w literaturze polskiej utożsamiany jest z szeroko rozumianym współzarządzaniem. O trudnościach definicyjnych i translatorskich tego pojęcia szerzej pisze A. Pawłowska (2016). Natomiast sformułowanie new rural governance stosowane jest w literaturze zagranicznej z zakresu badań obszarów wiejskich (rural studies). 
Martin 2005: 58). Wychodzą także poza tradycyjne rozumienie zarządzania (z dominującą rolą władz), kładąc nacisk na sposób, w jaki władze i pozostali aktorzy ze sobą współpracują (Murdoch, Abrams 1998: 41).

Literatura na temat współzarządzania pojawiła się pierwotnie w odniesieniu do perspektywy centralnej, państwowej, następnie do zagadnień miejskich, jednak z pominięciem badań obszarów wiejskich (Edward s i in. 2001; Goodwin 1998) i problematyki równości płci (Little 2001, 2002; Shortall 2002). Współcześnie można znaleźć opracowania (głównie jednak zagraniczne), w których podejmuje się rozważania na temat równości płci we współzarządzaniu obszarami/gminami wiejskimi. Równość płci staje się zagadnieniem ważnym, gdyż jest uznawana za istotny warunek wstępny rozwoju wsi (Shortall 2006). Zwiększenie stopnia autonomii i samostanowienia podmiotów tego procesu (a kobiety niewątpliwie nimi są) stanowi bowiem zarówno czynnik ich indywidualnego rozwoju, jak i rozwoju większej zbiorowości.

Tradycyjnie relacje między płciami (także między mieszkańcami a władzą) opierały się na podporządkowaniu mężczyznom, którzy zwyczajowo pełnili role decyzyjne. Sfera publiczna na wsi była więc domeną mężczyzn. Realizowali oni w niej przede wszystkim role zawodowe i związane ze sprawowaniem władzy, które często wymagały odpowiednich kwalifikacji, wykształcenia, dysponowania odpowiednim dochodem lub/i prestiżem społecznym.

Za sprawą zachodzących makroprocesów społecznych i gospodarczych ${ }^{2}$, zwłaszcza po II wojnie światowej, na wsi stopniowo zaczęły dokonywać się przeobrażenia społeczno-ekonomiczne. Zmieniła się znacząco struktura agrarna i społeczna wsi, sukcesywnie adaptowane są nowe wzorce kulturowe, a w ślad za nimi tworzą się nowego typu relacje między członkami wiejskich zbiorowości (także relacje między płciami) (por. np. Bock, Derkzen 2008; Kawczyńska-Butrym 2019). Przeobrażenia obszarów wiejskich mają zatem olbrzymi wpływ na życie kobiet i stanowią potencjał zmian w relacjach między nimi a mężczyznami. Do zmiany pozycji społecznej kobiet poprzez włączanie ich obecności w sferze publicznej nieustannie przyczynia się szeroko zakrojona działalność ruchów feministycznych. Także do polityk centralnych wprowadza się narzędzia polityczne (tzw. gender mainstreeming), służące rozprzestrzenianiu idei równości płci (por. Shortall, Bock 2015).

Koncepcja współzarządzania (new governance), w świetle idei równouprawnienia płci i poprawy pozycji społecznej kobiet (także w sferze publicznej), wydaje się zatem niezwykle obiecująca, opiera się bowiem na takich filarach jak partycypacja, obywatelstwo czy upodmiotowienie (Bock 2004). Z drugiej zaś strony, w jej praktycznym zastosowaniu pojawia się wiele barier, tkwiących zarówno w samych kobietach, jak i w ich wciąż konserwatywnym otoczeniu.

${ }^{2} \mathrm{~Np}$. urbanizacja, industrializacja, urynkowienie systemu gospodarczego, przystąpienie do struktur unijnych itp. 
Wyniki dotychczasowych badań empirycznych w zakresie uczestnictwa kobiet w życiu publicznym na wsi nie są jednoznaczne. $Z$ jednej strony wyniki wydają się dość zadowalające, gdyż badacze zauważają pozytywne ilościowe zmiany w liczbie aktywnych kobiet (np. O'Toole, Macgarvey 2003: 184; Bock 2010; Pięta-Szawara 2019). Z drugiej zaś strony wciąż przybywa dowodów na fasadowość tego uczestnictwa, a czasem wręcz na jego brak (Pini 2006). Samo „liczenie głów” może zatem nie być wystarczające i warto badać, czy kobiety i mężczyźni uczestniczą we współzarządzaniu na równych warunkach, w jakich rolach, a jeśli istnieją bariery wykluczenia, to jakie są tego przyczyny (Little, Jones 2000; Pini 2006).

Celem artykułu jest znalezienie odpowiedzi na pytanie, czy popularyzowana i częściowo wdrażana na obszarach wiejskich koncepcja współzarządzania (tzw. new rural governance) umożliwiła, tradycyjnie marginalizowanym w sferze publicznej, kobietom udział we współzarządzaniu gminą? Jednym z częściej przywoływanych przykładów współzarządzania w gminach wiejskich jest funkcjonowanie sieci Lokalnych Grup Działania (LGD). Możliwych form uczestnictwa jest oczywiście znacznie więcej, jak np. indywidualne angażowanie się w konsultacje społeczne, lokalne wybory (samorządowe czy sołeckie), tworzenie i uczestnictwo w komitetach czy organizacjach działających na rzecz rozwiązywania ważnych dla gminy problemów, a także pełnienie funkcji wójta, radnego czy sołtysa. Rozważania zaprezentowane w niniejszym tekście opierają się na analizie międzynarodowej literatury przedmiotu i będą skoncentrowane na określeniu zakresu uczestnictwa w szeroko rozumianym współzarządzaniu gminą i jego uwarunkowań.

\section{Współzarządzanie, czyli new governance}

Proces lokalnego zarządzania przeszedł transformację, od całkowicie centralnie kształtowanego przez państwo (tzw. government) do wzmacniającego zaangażowanie i inicjatywy lokalne, zarówno publicznych, jak i prywatnych podmiotów (governance), także przy wsparciu międzynarodowych organizacji, jak np. Bank Światowy czy Unia Europejska ${ }^{3}$ (Goodwin 1998; Rhodes 1996). Preferowaną formą działania, angażującą różne podmioty społeczeństwa, stało się tworzenie $\operatorname{sieci}^{4}$. Hierarchiczne powiązania organów oraz mechanizmy wydawania poleceń zastępowane są angażowaniem we współpracę podmiotów spoza administracji ${ }^{5}$, z wykorzystaniem mechanizmów decentralizacji lub technik nakłaniania, perswazji czy przekonywania (Stoker 1998). W ten sposób zmianie ulegają nie tylko rola organizacji i stowarzyszeń czy władz publicznych, ale również relacje między

\footnotetext{
${ }^{3}$ W literaturze przedmiotu zostało określone mianem przejścia od government do governance.

${ }^{4}$ LGD są przykładem takich sieci.

${ }^{5} \mathrm{~Np}$. organizacji pozarządowych, biznesu, indywidualnych aktorów itp.
} 
tymi podmiotami. Działanie w myśl koncepcji współzarządzania (new governance) wiąże się bowiem z koniecznością przekazania przez dominujące niegdyś podmioty publiczne części swoich kompetencji innym. Zaciera to granice pomiędzy sektorami, a także rodzi konieczność współpracy, tworzy szereg współzależności przy jednoczesnym zachowaniu autonomii każdej ze stron (Rhodes 2007; Stoker 1998).

Współzarządzanie przynosi wiele korzyści, ale również rodzi nowe problemy. Wśród zalet wymienia się wzrost bardziej demokratycznego uczestnictwa obywateli (np. większe możliwości udziału w procesach decyzyjnych), rozszerzenie struktur decyzyjnych o szerszy zakres grup interesariuszy (Cheshire, Higgins, Lawrence 2006), zwiększenie jawności, uczciwości i odpowiedzialności w rządzeniu, wzrost zaufania społecznego wobec instytucji i procesów politycznych, przejrzystość ról i powiązań instytucji w procesach legislacyjnych i wykonawczych, efektywność w realizowaniu celów itp. Ponaddwudziestoletnie doświadczenie w implementacji różnych elementów współzarządzania dowiodło jednak, że ta idealistyczna koncepcja w praktyce niejednokrotnie miewa fasadowy, a nawet utopijny charakter (Offe 2012). Krytyka odnosi się także do nieformalnych relacji między podmiotami, często niezgodnych z prawem i trudnych do udowodnienia. Problemem staje się niechęć do dzielenia się władzą, a także ustalenie podmiotu odpowiedzialnego za kolektywnie podejmowane decyzje, będące często wypadkową wielu sprzecznych oczekiwań. Ponadto zaobserwowano, że współzarządzanie, wbrew ideałom inkluzyjności, sprzyja pojawianiu się nowych form nierówności, a niekiedy wręcz wykluczaniu pewnych grup społecznych (Eversole, Martin 2005; Goodwin 1998; Herbert-Cheshire, Higgins 2004).

\section{Pozycja kobiet w życiu publicznym na wsi}

Kobiety zamieszkujące obszary wiejskie od lat stanowią interesujący obiekt badań zarówno wśród badaczy polskich (np. Tryfan 1968), jak i zagranicznych (np. Little, Panelli 2003). Dzieje się to za sprawą ,specyficznej” roli i pozycji społecznej przypisywanej kobietom na wsi oraz jej stopniowym przemianom. Początkowo zainteresowania badawcze skupiano na obserwacji relacji domowych między kobietami a mężczyznami, niewykraczających poza sferę prywatną. W latach 90., jak zauważają Little i Panelli (2003), badania przyjęły „,zwrot kulturowy" - zaczęto bowiem badać sposób, w jaki nierówne relacje i przekonania dotyczące płci są wytwarzane i utrzymywane w społecznym otoczeniu. Z dzisiejszej perspektywy oba nurty badań wciąż wydają się interesujące i przynoszą wiele ciekawych spostrzeżeń. Przede wszystkim jednak pozwalają zaobserwować tendencje zmian pozycji społecznej kobiet na wsi na tle zmian zachodzących w środowisku wiejskim oraz czynniki na nie wpływające.

Role społeczne kobiet i mężczyzn na wsi kształtowane były na bazie tradycyjnie ukształtowanych wzorów. Kobiety (żony-matki) koncentrowały swą 
działalność na domu, opiece nad rodziną i gospodarstwie, będąc jednocześnie całkowicie podporządkowanymi męskim żywicielom rodziny. Mężczyznom (ojcom-mężom-gospodarzom) zaś przypisana była rola głowy rodziny, nieomylnego decydenta i najczęściej właściciela dobytku.

Patriarchalne struktury rodzinne i tradycje kulturowe implikowały szereg ograniczeń i nierówności, zwłaszcza pod względem dochodów i zatrudnienia. Druga połowa XIX w., za sprawą dynamicznego rozwoju przemysłu, a także pogarszającej się sytuacji ekonomicznej rodzin, przyniosła zmianę w sytuacji zawodowej mieszkańców wsi, a zwłaszcza kobiet, których działalność coraz śmielej zaczęła wychodzić ze sfery prywatnej do publicznej. Tam również mężczyźni, zwyczajowo, posiadali autorytet i kontrolę, podczas gdy od kobiet oczekiwano angażowania się w działania wychowawcze, usługowe, pielęgnacyjno-opiekuńcze i podtrzymujące tradycyjne wartości wewnątrz społeczności (Malinowska 1998). Kobietom przypisana była aktywność związana z działalnością religijną i organizacyjną (np. w kołach gospodyń wiejskich, choć i one pierwotnie stanowiły wsparcie lub zaplecze kółek rolniczych). Ponadto kobiety miały pełne prawo uczestniczyć w życiu politycznym dzięki przyznanym im już w 1918 roku prawom wyborczym, choć nie korzystały z niego zbyt często.

Mimo potencjalnie wielu form uczestnictwa publicznego kobiet na wsi, to właśnie praca zawodowa stała się pierwszym znaczącym obszarem aktywności w sferze publicznej ${ }^{6}$, w którym ich obecność zaczęła się liczyć (Malinowska 1989; Tryfan 1969). Wraz z rosnącym zatrudnieniem kobiet mieszkających na wsi, płatna praca zaczęła zajmować ważniejsze miejsce w ich życiu i kształtowaniu tożsamości (Bock 2006). Zmianie uległy także relacje wynikające z pracy w rolnictwie, niegdyś dominującej formie gospodarki wiejskiej. Mężczyźni z reguły byli właścicielami gospodarstw rolnych, kontrolowali więc pracę kobiet i podejmowali w ich imieniu decyzje. Z czasem jednak, ze względów ekonomicznych małe gospodarstwa rodzinne były zastępowane gospodarstwami wielkoobszarowymi (agrobiznes), a wraz z nimi paternalistyczne stosunki płci zaczęły ulegać erozji. Kobiety stawały się nie tylko właścicielkami, ale i kierownikami gospodarstw rolnych. Rolniczki stały się uczestniczkami życia publicznego (por. Gorlach, Drąg 2019). Dzięki pracy zawodowej kobiety uzyskały większą niezależność ekonomiczną, stopniowo umacniając swoją pozycję w lokalnej zbiorowości. Współcześnie aktywność publiczna mieszkanek wsi jest, w większym stopniu niż dawniej, ściśle związana z ich pracą zawodową, także poza wsią zamieszkania. Są to pracownice lokalnej administracji, domów kultury i sołtyski (Desperak 2008).

${ }^{6}$ Sferę publiczną wypełniają role związane z produkcją rolniczą i kierowaniem gospodarstwem, pracą zawodową poza gospodarstwem, ze sprawowaniem władzy publicznej, działalnością w organizacjach i instytucjach sformalizowanych i niesformalizowanych, działalnością wykonywaną na rzecz swoich społeczności lokalnych, uczestnictwem w działaniach o charakterze politycznym (zainteresowanie polityką, udział w wyborach, kampanii wyborczej itp.). 


\section{Uczestnictwo kobiet w strukturach (wspól)zarządzających na wsi i jego bariery}

Wśród polityków podzielany jest konsensus co do dążenia do równości płci zarówno w sektorze rolniczym, jak i polityce wiejskiej, mimo to mężczyźni wciąż dominują w gremiach politycznych (Oedl-Wieser 2006). Kobietom często także brakuje chęci do uczestniczenia w życiu publicznym, co D. Walczak-Duraj (2008) thumaczy uwarunkowaniami mentalno-społecznymi, takimi jak: brak doświadczenia i wiedzy na temat uczestnictwa, niska pozycja aktywności publicznej w systemie aksjonormatywnym, niska ocena zaangażowania ze strony innych kobiet.

Jednocześnie badania dowodzą, że udział kobiet na arenie publicznej systematycznie wzrasta (O'Toole, Macgarvey 2003; Bock 2010; Panelli, Pini 2005; Pięta-Szawara 2019). Wyraźna jest jednak prawidłowość, z której wynika, że liczba kobiet w sferze publicznej wzrasta wraz ze zmniejszaniem się zakresu decyzyjności zajmowanych przez nie stanowisk. Na wsi najwięcej kobiet odnajdziemy wśród sołtysek, następnie radnych, a znacznie rzadziej wśród wójtów. W przypadku struktur, w których uczestnictwo jest „,skromnie obsadzone i skromnie zasilane", kobiety są z reguły chętniej widziane (Sheridan, Pini, Conway 2006). Przykłady międzynarodowych badań (Thue sen 2016) potwierdzają także, że w sieciach LGD kobiety rzadziej niż mężczyźni były członkiniami decyzyjnymi. Oznacza to, że w organach dysponujących znacznymi zasobami i/lub władzą polityczną mężczyźni nadal zachowują dominującą pozycję. Ponadto, kobiety na wsi, które biorą udział w życiu publicznym, częściej decydują w sprawach operacyjnych, mężczyźni zaś w odniesieniu do długofalowych i strategicznych planów (Little, Jones 2000). Także analiza Programu Rozwoju Obszarów Wiejskich w tzw. państwach unijnych pokazała, że kobiety rzadko biorą udział w tworzeniu planów rozwoju obszarów wiejskich i rzadziej niż mężczyźni podejmują decyzje dotyczące podziału funduszy (Bock 2010). Sheridan, Pini i Conway (2006) wyciągnęli krytyczne wnioski z Raportu reprezentacji kobiet $w$ governance w Australii, konkludując, że mimo iż kobiety zwiększyły swoją reprezentację na wybranych stanowiskach, to nadal zajmują marginalną pozycję.

Wiejskie aktywistki postrzegają sferę polityki jako rządzącą się własnymi, męskimi prawami. Sobie przypisują funkcje organizacyjne i wspierające (Desperak 2008). Rzadko aspirują do stanowisk decyzyjnych. Same wolą się angażować w nieformalne działania, postrzegane jako łatwiejsze i mniej konkurencyjne, zajmując się kwestiami, które bardziej związane są z ich codziennym życiem (Bock 2015: 7). Często ich zaangażowanie motywowane jest wysokim poczuciem odpowiedzialności za edukację dzieci oraz obowiązkiem niesienia pomocy potrzebującym. W tym obszarze realizują się także poprzez pracę w stowarzyszeniach i fundacjach (Walczak-Duraj 2008). W lokalnej administracji najczęściej zajmują stanowiska kojarzone z kobiecymi sferami oddziaływania, tj. edukacją i opieką nad dziećmi (Desperak 2008). 
Nierówności w reprezentacji kobiet wynikają również z tego, że rekrutacja do sieci współpracy dokonywana i zdominowana jest przez mężczyzn (Thuesen 2016). Nabór odbywa się bowiem poprzez sugestie organizacji rolniczych ${ }^{7}$ lub, jak to ma miejsce w przypadku struktur LGD w Polsce, władz lokalnych, a te zazwyczaj są zdominowane przez mężczyzn (Thuesen, Derkzen 2015). Nowe instytucje zarządzania obszarami wiejskimi, opierające się na idei współzarządzania, preferują elity lokalne. Wiejska sfera publiczna jest zaś tradycyjnie zdominowana przez mężczyzn. Ponadto męski charakter wielu sieci biznesowych ułatwia im zaangażowanie w programy partnerskie. Jest to, jak zauważa B ock (2004), faworyzowanie mężczyzn. Nawet gdy kobiety uczestniczą jako członkowie w różnych inicjatywach, to ich głosy i perspektywy mogą być marginalizowane przez dominujących w tej sferze mężczyzn (Bock 2004; Bock, Derkzen 2003; Pini 2006; Grant, Rainnie 2005).

Badania wśród aktywnych publicznie kobiet na wsi wskazują także na zjawisko ich wewnętrznego wykluczenia. Style spotkań i żargon na nich używany są zorientowane na współzawodnictwo i konflikt oraz skoncentrowane na rozwoju ekonomicznym, kojarzonym z męskimi cechami i sferami działania. Nacisk na współpracę $z$ sektorem prywatnym ${ }^{8}$ dodatkowo legitymizuje i wzmacnia męskie sposoby działania, przez co także marginalizuje kobiety i kobiecą podmiotowość (Little, Jones 2000). Przykładowo, praktyki rewitalizacyjne są zdominowane przez sferę inwestycji, budownictwa i ekonomii, te zaś powszechnie uważane są za męskie (Little, Jones 2000). Kobiety natomiast w większym stopniu są zainteresowane kwestiami jakości życia i oczekują bardziej konsensualnych form spotkań (Little, Jones 2000; Tickell, Peck 1996; Thuesen 2016). Polityka wiejska, tworzona przez mężczyzn, skupia się także na obszarach „bardziej męskich" (Little, Jones 2000). W dyskusjach publicznych dominują problemy związane z gospodarką, co może oznaczać, że obywatelstwo polityczne kobiet na wsi jest w dużym stopniu uzależnione od ich obywatelstwa gospodarczego (Bock 2008: 273).

Kobieca aktywność we współzarządzaniu nie spotyka się z akceptacją otoczenia (Pini 2006). Przykładowo, badania reakcji mężczyzn pełniących ważne role w polityce lokalnej (np. radny, burmistrz) na udział nowych aktorek w sferze publicznej wskazywały np., że kobiety były wykluczane z wiedzy i sieci, a kobietę burmistrz uważano za niepasującą do tradycyjnych schematów tożsamości w społeczności wiejskiej (Pini 2006).

Większemu zaangażowaniu kobiet we współzarządzanie nie sprzyjają także media, bowiem prezentując obraz wiejskiej idylli, ukazują kobiety i mężczyzn w tradycyjnych rolach (kobiety w roli matki i gospodyni domowej), a tym samym

${ }^{7}$ W Danii zasady określające skład zarządów LGD wymagają reprezentacji organizacji rolniczych.

${ }^{8} \mathrm{~Np}$. w strukturach LGD. 
wspierają nierówności płci na wsi. Rzadko ukazywane są kobiety w rolach publicznych, np. radnej, działaczki, aktywistki. To z kolei przyczynia się do ograniczania możliwości wyboru przez kobiety ról np. zawodowych (Little, Austin 1996).

Zdaniem badaczek B. Bock i P. Derkzen (2007), dwa zestawy czynników ograniczają dostęp kobiet do uczestnictwa w strukturach współzarządzających polityką na wsi. Pierwszy z nich tworzy wciąż tradycyjny charakter porządku płci, zarówno w strukturach społecznych, jak i dominującej kulturze. Drugi dotyczy struktury i kultury zaangażowania we współzarządzanie. Tworzą go np. formalne zasady działania i ich nieznajomość wśród kobiet, stosowanie profesjonalnego języka (kobiety nie posiadają na ogół zawodowego przygotowania), dominacja gospodarczego dyskursu, brak szacunku dla wiedzy społecznej i problemów jakości życia (obszarów ważnych dla kobiet). Na słabszą partycypację kobiet wpływ mają także brak zasobów finansowych, brak wsparcia instytucjonalnego, brak kapitału politycznego (Bock, Derkzen 2007).

Przytoczone w niniejszym tekście wyniki prac badawczych, mimo że wskazują na szereg barier, które niewątpliwe należy eliminować, uzmysławiają jednak, iż część kobiet mimo wszystko jest aktywna w sferze publicznej. Ich zaangażowanie we współzarządzanie jest jednak zróżnicowane i zależne od poziomu społeczno-ekonomicznego rozwoju struktury, w której funkcjonują. Obszary wiejskie są kategorią bardzo zróżnicowaną. Odsetek kobiet zarządzających w LGD wzrasta wraz z poziomem urbanizacji i centralnym położeniem gminy (Thu esen, Derkzen 2015). Relacje płci, jako jedno z istotniejszych uwarunkowań uczestnictwa kobiet na obszarach wiejskich, są także silnie zróżnicowane ze względu na konkretną kulturę i przestrzeń (Shortal, Bock 2015a). Zjawisko nierówności płci, jak wskazuje B. Bock (2010), częściej obserwowane jest na peryferyjnie położonych obszarach wiejskich i w Europie Środkowej i Wschodniej.

\section{Zakończenie}

Idea współzarządzania niosła ze sobą nadzieję na zwiększone uczestnictwo kobiet w sferze publicznej. Badania wskazują jednak na to, że w praktyce bywa inaczej. Choć zakres uczestnictwa kobiet we współzarządzaniu nominalnie zwiększa się, to realnie jest często ograniczony do uczestnictwa, bez możliwości wpływu oraz często ma fasadowy charakter. Mimo retoryki inkluzji new governance, nowe struktury współzarządzania mają duży potencjał wykluczający, zarówno o zewnętrznym, jak i wewnętrznym charakterze.

Bariery uczestnictwa we współzarządzaniu gminą tworzą nadal uwarunkowania mentalno-środowiskowe kobiet i ich otoczenia, a także sama koncepcja współzarządzania.

Strukturalne i kulturowe cechy polityki wiejskiej, które niegdyś były uznawane za ograniczające uczestnictwo kobiet, są niestety nadal obecne. Jak słusznie 
zauważa B. Bock (2008: 278), dzieje się tak dlatego, że pozycja kobiet w społeczeństwie wiejskim i cechy porządku płci niewiele się zmieniły. Normy kulturowe sprzyjające wykluczaniu kobiet z pełnego uczestnictwa w życiu gospodarczym i społeczno-politycznym są wciąż wszechobecne (Grant, Rainnie 2005: 178).

Koncepcja współzarządzania, w której paradoksalnie kładzie się nacisk na uspołecznienie samego procesu zarządzania, przyjmuje a priori, że dzięki uczestnictwu potencjalnie zainteresowanych stron zostanie osiągnięty pożądany cel działania. Sam fakt uczestnictwa nie gwarantuje jednak wpływu na decyzje. Kluczowe staje się nie tylko bierne uczestnictwo w poszczególnych etapach zarządzania (analizowaniu, planowaniu, decydowaniu, realizacji czy kontrolowaniu), ale realny na nie wpływ.

Trudno zatem nie przyznać racji autorom, którzy twierdzą, że nie ma nic nowego we współzarządzaniu (new goveranace) w odniesieniu do kwestii płci i zarządzania na obszarach wiejskich (Little, Jones 2000; Pini 2006; B ock 2010), gdyż nowo powstające struktury pozostają pod wpływem starych struktur (Oed1-Wies er 2015: 6), mocno zakorzenionych w patriarchacie.

Warto zatem przestrzec, za A. Sheridan, B. Pini i L. Conway (2006), przed wyrażaniem poglądów, że zwiększony udział kobiet w nowych formach współzarządzania jest symptomem zmian w wiejskich relacjach władzy między płciami. Nierówność płci jest nadal strukturalną i, jak można wnioskować, trwałą cechą wsi (Shortall, Bock 2015: 662). Jest to jednak zagadnienie, które wciąż warto badać, zwłaszcza na obszarach wiejskich w Polsce, które w tym kontekście są słabo rozpoznane.

\section{Bibliografia}

Bock B. B. (2004), It Still Matters Where You Live: Rural women's employment throughout Europe, [w:] H. Buller, K. Hoggart (eds.), Women in the European Countryside, Ashgate, Aldershot, s. $14-41$.

Bock B. B. (2006), Introduction: Rural gender studies in North and South, [w:] B. B. Bock,

S. Shortall (eds.), Rural Gender Relations: Issues and case-studies, CABI, Oxfordshire, s. $1-18$.

Bock B. B. (2010), Personal and Social Development of Women in Rural Areas of Europe, European Parliament.

Bock B. B. (2015), Gender Mainstreaming and Rural Development Policy: The Trivialisation of Rural Gender Issues, „Gender, Place \& Culture”, nr 22 (5), s. 731-745.

Bock B. B., Derkzen P. (2006), Gender and Rural Development Budgets, [w:] B. B. Bock, S. Shortall (eds.), Rural Gender Relations: Issues and case-studies, CABI, Oxfordshire, s. 224-241.

Bock B. B., Derkzen P. (2007), Barriers to Women's Participation in Rural Policy Making, [w:] I. Asztalos Morell, B. B. Bock (eds.), Gender Regimes, Citizen Participation and Rural Restructuring, Elsevier, Amsterdam, s. 265-283.

Cheshire L., Higgins V., Lawrence G. (eds.) (2006), Rural Governance: International perspectives, Routledge. 
Desperak I. (2008), Gmina jako środowisko społeczno-politycznej aktywności kobiet wiejskich, [w:] J. Krzyszkowski (red.), Diagnoza sytuacji spoteczno-zawodowej kobiet wiejskich w Polsce, Warszawa, s. 107-124.

Dryzek J. S. (2002), Deliberative democracy and beyond: Liberals, critics, contestations, Oxford University Press on Demand.

Edwards B., Goodwin M., Pemberton S., Woods M. (2001), Partnership, Power and Scale in Rural Governance, „Environment and Planning C: Government and Policy”, nr 19 (2), s. 289-310.

Eversole M. J. (2005), Introduction: Participation and governance in regional development, [w:] R. Eversole, J. Martin (eds.), Participation and Governance in Regional Development. Global trends in an Australian context, Ashgate, Aldershot, s. 1-14.

Goodwin M. (1998), The Governance of Rural Areas: Some emerging research issues and agendas, „Journal of Rural Studies”, nr 14 (1), s. 5-12.

Gorlach K., Drąg Z. (2019), Rolniczki jako uczestniczki życia społecznego, „Acta Universitatis Lodziensis. Folia Sociologica", nr 68, s. 47-66.

Grant J., Rainnie A. (2005), The Hidden Role of Gender Exclusion in Regional Development Agencies, [w:] R. Eversole, J. Martin (eds.), Participation and Governance in Regional Development, Ashgate, Oxenbridge, s. 211-228.

Herbert-Cheshire L., Higgins V. (2004), From Risky to Responsible: Expert Knowledge and the Governing of Community-Led Rural Development, „Journal of Rural Studies”, nr 20 (3), s. $289-302$.

Kawczyńska-Butrym Z. (2019), Kobiety - mieszkanki wsi-aktywność i zmiana, „Acta Universitatis Lodziensis. Folia Sociologica", nr 68, s. 5-15.

Little J. (2001), New Rural Governance?, „Progress in Human Geography”, nr 25 (1), s. 97-102.

Little J. (2002), Gender and Rural Geography, Pearson, Essex.

Little J., Austin P. (1996), Women and the Rural Idyll, „Journal of Rural Studies”, nr 12 (2), s. $101-111$.

Little J., Jones O. (2000), Masculinity, Gender and Rural Policy, „Rural Sociology”, nr 65 (4), s. 621-639.

Little J., Panelli R. (2003), Gender Research in Rural Geography, „Gender, Place and Culture: A Journal of Feminist Geography", nr 10 (3), s. 281-289.

Malinowska E. (1998), Pozycja społeczna kobiet wiejskich, „Przegląd Socjologiczny”, nr 47 (2).

Murdoch J., Abram S. (1998), Defining the Limits of Community Governance, ,Journal of Rural Studies", nr 14 (1), s. 41-50.

O'Toole K., Macgarvey A. (2003), Rural Women and Local Economic Development in SouthWest Victoria, „Journal of Rural Studies”, nr 19 (2), s. 173-186.

Oedl-Wieser T. (2006), Frauen und Politik am Land, „Public Observer”, nr 33, s. 2-3.

Oedl-Wieser T. (2015), Gender Equality: A core dimension in Rural Development Programmes in Austria?, „Gender, Place \& Culture”, nr 22 (5), s. 685-699.

Offe C. (2012), Governance - „puste pojęcie” czy naukowy problem badawczy?, „Zarządzanie Publiczne", nr 3 (21), s. 81-107.

Panelli R., Pini B. (2005), “This Beats a Cake Stall!': Farm women's shifting encounters with the Australian state, „Policy \& Politics”, nr 33 (3), s. 489-503.

Pawłowska A. (2016), Governance jako podejście teoretyczne - kilka kwestii spornych, „Polityka i Społeczeństwo", nr 3 (14), s. 5-17.

Pięta-Szawara A. (2019), Milczaca nieobecność. Uczestnictwo polityczne kobiet na obszarach wiejskich, „Acta Universitatis Lodziensis. Folia Sociologica”, nr 68, 17-31.

Pini B. (2006), A Critique of 'New' Rural Local Governance: The case of gender in a rural Australian setting' „Journal of Rural Studies”, nr 22 (4), s. 396-408. 
Idea współzarządzania - szansa czy ograniczenie uczestnictwa publicznego kobiet na wsi 91

Pini B., McDonald P. (2013) (eds.), Women and Representation in Local Government: International case studies, Routledge, London.

Rhodes R. A. (1997), Understanding Governance: Policy networks, governance, reflexivity and accountability, Open University Press.

Rhodes R. A. (2007), Understanding Governance: Ten years on, „Organization Studies”, nr 28 (8), s. $1243-1264$.

Rhodes R. A. W. (1996), The New Governance: Governing without government. „Political Studies", nr 44 (4), s. 652-667.

Sheridan A., Pini B., Conway L. (2006), Modestly Staffed and Modestly Resourced: An Exploratory Critique of Women's Entry to Rural and Regional Governance, „Rural Society”, nr 16 (3), s. 271-282.

Shortall S. (2002), Gendered Agricultural and Rural Restructuring: A case study of Northern Ireland, "Sociologia Ruralis", nr 42 (2), s. 160-176.

Shortall S. (2006), Gender and Farming: An overview, [w:] B. B. Bock, S. Shortall (eds.), Rural Gender Relations: Issues and case studies, CABI, Oxfordshire, s. 19-26.

Shortall S., Bock B. B. (2015), Introduction. Rural Women in Europe: The impact of place and culture on gender mainstreaming the European Rural Development Programme, „Gender, Place \& Culture", nr 22 (5), s. 662-669.

Stoker G. (1998), Governance as Theory: Five Propositions, „International Social Science Journal", nr 50 (155), s. 17-28.

Thuesen A. (2016), Gender and Rural Governance, [w:] M. Shucksmith, D. L. Brown (eds.), Routledge International Handbook of Rural Studies, Routledge, Taylor \& Francis eBooks, s. 379-388.

Thuesen A. A., Derkzen P. (2016), Questioning the Gender Distribution in Danish LEADER LAGs, [w:] L. Grandberg, K. Anderson, I. Kovach (eds.), Evaluating the European Approach to Rural Development: Grass-roots Experiences of the LEADER Programme, s. 127-148.

Tickell A., Peck J. (1996), The Return of the Manchester Men: Men's Words and Men's Deeds in the Remaking of the Local State, „Transactions of the Institute of British Geographers”, nr 21 (4), s. 595-616.

Tryfan B. (1968), Pozycja społeczna kobiety wiejskiej, Książka i Wiedza, Warszawa.

Walczak-Duraj D. (2008), Potencjał i specyfika kapitału społecznego kobiet funkcjonujacych w środowisku wiejskim, „Przegląd Socjologiczny”, nr 57 (1), s. 105-134.

\section{Małgorzata Marks-Krzyszkowska, Jarosław Linka}

\section{NEW RURAL GOVERNANCE - OPPORTUNITY OR RESTRICTION ON THE PUBLIC PARTICIPATION OF RURAL WOMEN}

\footnotetext{
Abstract. The paper looks at whether the concept of new rural governance, allows traditionally marginalized women in the public sphere to participate in communes management. The study are based on the analysis of international literature on this subject and focus on determining the scope of participation in the broadly understood governance of the commune and the possible causes of its limitations. As a conclusion, although women's participation in commune management has been nominally increasing, it is often limited to participation without real influence and often has an illusory character.
}

Key words: rural women, new rural governance, public participation. 